(c) American Dairy Science Association, 2006.

\title{
Properties of Cholesterol-Reduced Butter Made with $\beta$-Cyclodextrin and Added Evening Primrose Oil and Phytosterols
}

\author{
J. J. Kim, T. H. Jung, J. Ahn, and H. S. Kwak ${ }^{1}$ \\ Department of Food Science and Technology, Sejong University, Seoul 143-747, Korea
}

\begin{abstract}
The present study was carried out to examine changes in the chemical and sensory properties of butter in which the cholesterol was reduced and to which evening primrose oil (EPO) and phytosterols were added. Crosslinked $\beta$-cyclodextrin ( $\beta$-CD) made from adipic acid was used, and approximately $90 \%$ of the cholesterol was removed. The color measurement values " $L$ " and "a" were significantly different between the control (butter with no $\beta$-CD treatment and no added EPO and phytosterols) and treatment A (butter treated with $10 \%$ crosslinked $\beta$-CD); however, the color values for " $\mathrm{L}$ " and "a" were similar. The color value " $\mathrm{b}$ " in treatment B (butter treated with $10 \%$ crosslinked $\beta$ $\mathrm{CD}$ and 5\% phytosterols and 3\% EPO added) was significantly higher than in the other treatments. The thiobarbituric acid value of treatment B was significantly higher than that of the control and treatment A. Scores for hardness, elasticity, and cohesiveness were significantly lower in the control than in treatment A. Differences in sensory characteristics did not result from the $\beta$-CD treatment but from the addition of EPO and phytosterols. In microscopic examinations, no noticeable differences were found among the treatments, and a smooth texture and a fine, uniform crystalline structure were observed. Results indicated that about $90 \%$ of the cholesterol was reduced by crosslinked $\beta$-CD and that the $\beta$-CD treatment itself did not adversely influence the chemical and sensory properties of the butter. However, the addition of EPO and phytosterols to the butter appeared to impair its sensory properties, especially in terms of rancidity and overall acceptability.
\end{abstract}

Key words: cholesterol-reduced butter, crosslinked $\beta$ cyclodextrin, evening primrose oil, phytosterols

\section{INTRODUCTION}

In the past decades, $44 \%$ of Americans have changed their eating habits to lower their cholesterol level (Ar-

Received December 6, 2005.

Accepted March 31, 2006.

${ }^{1}$ Corresponding author: kwakhs@sejong.ac.kr thur, 1990). International Dairy Statistics (2003) reported that world per capita consumption of butter slowly decreased from 1999 to 2002 in most European countries, Asia, and the United States. This shift in eating habits has caused a dramatic increase in nocholesterol, low-cholesterol, and reduced-cholesterol and fat products available in the marketplace (Best, 1989). A manufacturer in New Zealand previously reported trial production of a reduced-cholesterol butter (Wilson, 1990), and consumer and industry demand has led to an interest in manufacturing reduced-cholesterol dairy products.

Previously, several studies have indicated that the cholesterol in food, including that in milk, yogurt, cream, and cheese, can be reduced effectively by $\beta$-cyclodextrin ( $\beta$-CD; Oakenfull and Sidhu, 1991; Kwak et al., 2002; Shim et al., 2003; Hwang et al., 2005; Kim et al., 2005; Kwak et al., 2005; Lee et al., 2006). Because $\beta$ CD is nontoxic, edible, nonhygroscopic, and chemically stable (Nagamoto, 1985), it has positive attributes when used for cholesterol removal from foods. Although using powdered $\beta$-CD allows for about $90 \%$ cholesterol removal, it may not be adequate for separating cholesterol from food systems and for $\beta$-CD reuse. Moreover, because of the high cost of $\beta$-CD and other operating expenses, $\beta$-CD is nearly impossible to apply to related manufacturing processes.

Crosslinking is a commonly used derivatization technique for manipulating starch functionality. Epichlorohydrin and adipic anhydride have been used extensively to produce crosslinked starches, in which interor intramolecular mono- and diethers are formed with hydroxyl groups of starch (Hamerstrand et al., 1959). The ability of crosslinked $\beta$-CD to remove cholesterol was found in several studies (Kim et al., 2004; Han et al., 2005; Kim et al., 2005), and $\beta$-CD also showed efficient cholesterol removal after recycling. Therefore, the manufacture of cholesterol-reduced butter could become practical by using crosslinked $\beta$-CD.

In addition to cholesterol removal, phytosterols and evening primrose oil (EPO) have recently gained considerable attention as nutraceuticals for their blood cholesterol-lowering efficacy (Ling and Jones, 1995; Leeson and Flöter, 2002). This interest has now been trans- 
lated into a range of health-promoting functional products, such as vegetable oil-based table spreads. Typically, the content of sterols is between 6 and $10 \%$ to provide sufficient daily intake for the blood cholesterollowering effect (Lesson and Flöter, 2002). The plasma cholesterol-lowering effect of a margarine containing phytosterol esters that were re-esterified with unsaturated fatty acids has been confirmed in humans (Weststrate and Meijer, 1998).

Most organizations concerned with cardiovascular health have recommended substantial increases in polyunsaturated fatty acid (PUFA) intake and decreases in saturated fat intake (Grundy et al., 1982; Expert Panel on Detection, 2001). This sustained campaign has led to large increases in PUFA intake in some countries, such as the United States, and such increases may in part be responsible for the recent decline in coronary disease mortality (Horrobin and Manku, 1983).

Among the PUFA, evening primrose (Oenothera spp., particularly Oenothera biennis) is of special interest because its seed contains an oil characterized by a high content of $\gamma$-linolenic acid (GLA, all cis-6,9,12-octadecatrienoic acid; Hudson, 1984). Despite numerous demonstrations of the cholesterol-lowering properties of PUFA such as GLA, the precise mechanism is still not fully understood (Sugano et al., 1986; Ihara-Watanabe et al., 1999). Large amounts of PUFA are required to produce a substantial and meaningful reduction in plasma cholesterol.

As another cholesterol-lowering compound, phytosterols (i.e., plant sterols) are natural components of the human diet that are structurally related to cholesterol (Hepburn et al., 1999). They are minor constituents present in the unsaponifiable fraction of edible vegetable oils, and the most important dietary sources are from vegetable oils in margarine. In nature, the most common phytosterols are the 4-desmethylsterols, namely, $\beta$-sitosterol, campesterol, and stigmasterol, and they occur in the FFA, sugar moieties, or phenolic acids (Hepburn et al., 1999). In Northern European countries, phytosterol intake from normal food sources has been estimated to be about $200 \mathrm{mg} / \mathrm{d}$ (Morton et al., 1995).

Based on this information, we assumed that the addition of EPO and phytosterols could enhance the cholesterol-lowering effect of cholesterol-reduced butter. This study was designed to develop a cholesterol-reduced butter with added EPO and phytosterols, and to examine the effects of EPO and phytosterol addition on the chemical and sensory properties of the butter.

\section{MATERIALS AND METHODS}

\section{Materials}

Separated and pasteurized cream (36\% milk fat) was obtained from the Binggrae Dairy Plant (Kyonggi-do,
Korea). Commercial $\beta$-CD (purity 99.1\%) was purchased from Nihon Shokuhin Cako Co. Ltd. (Osaka, Japan). Evening primrose oil and phytosterols (90\% soybean origin; $40 \% \beta$-sitosterol, $20 \%$ campesterol, and $10 \%$ stigmasterol) were obtained from Il-dong Pharmaceutical Co. (Seoul, Korea) and Dasol International (Seoul, Korea), respectively. Cholesterol and $5 \alpha$-cholestane were purchased from Sigma Chemical Co. (St. Louis, MO), and all solvents were of gas-chromatographic grade.

\section{Preparation of Crosslinked $\beta-C D$}

A 100 -g sample of $\beta$-CD was dissolved in $80 \mathrm{~mL}$ of distilled water and placed in a stirrer at room temperature with constant agitation for $2 \mathrm{~h}$. Adipic acid ( $2 \mathrm{~g}$ ) was then incorporated into the $\beta$-CD solution and the $\mathrm{pH}$ was adjusted to $\mathrm{pH} 10$ with $1 N \mathrm{NaOH}$. The $\beta$-CD solution was stirred at room temperature for $90 \mathrm{~min}$ and then readjusted to $\mathrm{pH} 5$ with acetic acid. $\beta$-Cyclodextrin was recovered by filtering with Whatman No. 2 filter paper and washing 3 times with $150 \mathrm{~mL}$ of distilled water. The product was dried at $60^{\circ} \mathrm{C}$ in a Lab-Line mechanical convection oven (O-Sung Scientific Co., Seoul, Korea) for $20 \mathrm{~h}$ and passed through a 100-mesh sieve (Han et al., 2005).

\section{Treatment of Cream}

Bulk pasteurized cream (15 kg) was stirred with $10 \%$ crosslinked $\beta$-CD at 1,400 rpm with a blender (Tops, Misung Co., Seoul, Korea) in a temperature-controlled water bath at $40^{\circ} \mathrm{C}$ for $30 \mathrm{~min}$. The cream was then centrifuged at $166 \times g$ for $\beta$-CD removal. All treatments were run in triplicate.

\section{Manufacture of Butter}

Three different experimental butters were manufactured: 1) control, made with cream not treated with $\beta$ $\mathrm{CD}$ and to which no EPO and phytosterols were added; 2) treatment (Trt) A, made with cream treated with $10 \%$ crosslinked $\beta$-CD (wt/wt) to which no EPO and phytosterols were added; and 3) Trt B, made with cream treated with $10 \%$ crosslinked $\beta$-CD to which $5 \%$ phytosterols and 3\% EPO were added. Phytosterols were dissolved in the EPO at a warm temperature $\left(\sim 50^{\circ} \mathrm{C}\right)$.

The treated cream was stored overnight in a refrigerator as an initial sample $(0 \mathrm{~d})$. The cream was kept at 13 to $14^{\circ} \mathrm{C}$ and churned using a mechanical butter churn (Manvelb A20; Elecrem, Navnes, France) until butter granules were visible. The buttermilk was drained off and the butter was washed in $10^{\circ} \mathrm{C}$ tap water. Salt $(1 \%)$ was then added and the butter was molded. After 
manufacture, the molded butter was weighed and placed in suitable containers to study the chemical, rheological, and sensory changes. Butter making was carried out in triplicate on different days using different batches of $\beta$-CD-treated creams.

\section{Extraction and Determination of Cholesterol}

For the extraction of cholesterol, $1 \mathrm{~g}$ of butter sample was placed in a screw-capped glass tube $(15 \times 180 \mathrm{~mm})$, and $1 \mathrm{~mL}$ of $5 \alpha$-cholestane $(1 \mathrm{mg} / \mathrm{mL})$ was added as an internal standard. The sample was saponified at $60^{\circ} \mathrm{C}$ for 30 min with $5 \mathrm{~mL}$ of $2 M$ ethanolic potassium hydroxide solution (Adams et al., 1986). After cooling to room temperature, the cholesterol was extracted with $5 \mathrm{~mL}$ of hexane (Adams et al., 1986). The process was repeated 4 times. The hexane layers were transferred to a roundbottomed flask and dried under vacuum. The extract was redissolved in $1 \mathrm{~mL}$ of hexane and stored at $-20^{\circ} \mathrm{C}$ until analysis.

Total cholesterol was determined on a fused-silica capillary column $(\mathrm{HP}-5,30 \mathrm{~m} \times 0.32 \mathrm{~mm}$ i.d. $\times 0.25$ $\mu \mathrm{m}$ thickness; Hewlett-Packard, Palo Alto, CA) using a Hewlett-Packard 5890A gas chromatograph equipped with a flame ionization detector. The injector and detector temperatures were 270 and $300^{\circ} \mathrm{C}$, respectively. The oven temperatures were programmed from 200 to $300^{\circ} \mathrm{C}$ at $10^{\circ} \mathrm{C} / \mathrm{min}$ and held for $20 \mathrm{~min}$. Nitrogen was used as a carrier gas at a flow rate of $2 \mathrm{~mL}$, with a split ratio of 1:50. Quantitation of cholesterol was done by comparing the peak areas with the response of an internal standard.

The percentage of cholesterol reduction was calculated as follows: cholesterol reduction $(\%)=100-$ (amount of cholesterol in $\beta$-CD-treated butter $\times 100$ / amount of cholesterol in the control). Cholesterol determination for the control was averaged with each batch of treatments.

\section{Analysis of Chemical Composition}

Butter was analyzed for moisture and fat using AOAC methods (AOAC, 1990). Butter yield was determined as (weight of butter $\times 100$ )/weight of cream.

\section{Color Measurement}

Samples containing phytosterols and EPO were measured at $4^{\circ} \mathrm{C}$. A colorimeter (Minolta CT-310; Konica Minolta Sensing, Inc., Osaka, Japan) was used for color measurement. Hunter "L" values $(100=$ perfect white; 0 = black) for lightness, and "a" (+ = redness; - = greenness) and "b" values $(+=$ yellowness, $-=$ blueness $)$ for chromaticities were measured. Each product was analyzed in 5 replicates.

\section{Thiobarbituric Acid Test}

Oxidation products were analyzed spectrophotometrically using the thiobarbituric acid (TBA) test (Hegenauer et al., 1979). The TBA reagent was prepared immediately before use by mixing equal volumes of freshly prepared $0.025 M$ TBA, which was neutralized with $1 N \mathrm{NaOH}$ solution and $2 M \mathrm{H}_{3} \mathrm{PO}_{4}-2 M$ citric acid. Reactions for the TBA test were started by placing $1 \mathrm{~g}$ of butter sample into a glass centrifuge tube and mixing thoroughly with $2.5 \mathrm{~mL}$ of TBA reagent. The mixture was heated immediately in a boiling water bath for exactly $10 \mathrm{~min}$ and cooled on ice. Ten milliliters of cyclohexanone and $1 \mathrm{~mL}$ of $4 M$ ammonium sulfate were added and centrifuged at $2,490 \times g$ for $5 \mathrm{~min}$ at room temperature. The orange-red cyclohexanone supernatant was decanted and its absorbance was measured spectrometrically at $532 \mathrm{~nm}$ in a 1-cm light path. All treatments were run in triplicate.

\section{Rheological Analysis}

Cylindrical samples $(2 \mathrm{~cm}$ diameter $\times 4.5 \mathrm{~cm}$ height $)$ were cut, and force-distance curves were obtained using a Sun Rheometer (CR-200D; Sun Scientific Co., Ltd., Tokyo, Japan) with a cross-head speed of $50 \mathrm{~mm} / \mathrm{min}$ and a chart speed of $100 \mathrm{~mm} / \mathrm{min}$. From these curves, the basic characteristics of the texture profile were determined, including hardness, elasticity, cohesiveness, gumminess, and chewiness. The point of highest force during the first compression was the hardness. The extent to which the sample returned to its shape between the first and second compressions was the elasticity. The ratio of the area under the second compression curve was the cohesiveness. Gumminess and chewiness were calculated as hardness $\times$ cohesiveness and gumminess $\times$ elasticity, respectively.

\section{Sensory Analysis}

For the sensory analysis, 10 trained panels evaluated the randomly coded butter. Texture, color, rancidity, acidity, and greasiness were evaluated on a 5-point scale $(1=$ very weak, $3=$ moderate, $5=$ very strong $)$. Overall preference was scored on a 5-point scale (1 = like extremely, 3 = neither like nor dislike, $5=$ dislike extremely). A randomized, balanced complete block design was used (Cochran and Cox, 1957), which resulted in 2 replications for all samples.

\section{Microscopic Observation}

For visualization of the morphological characterization of the extruded product, the butter sample was 
Table 1. Mean chemical composition of cholesterol-reduced butter manufactured with different treatments ${ }^{1}$

\begin{tabular}{lccc}
\hline Component (\%) & Control & Trt A & Trt B \\
\hline Fat & $79.6^{\mathrm{a}}$ & $80.3^{\mathrm{a}}$ & $79.1^{\mathrm{a}}$ \\
Moisture & $17.0^{\mathrm{b}}$ & $17.8^{\mathrm{ab}}$ & $19.0^{\mathrm{a}}$ \\
Protein & $1.3^{\mathrm{ab}}$ & $1.4^{\mathrm{a}}$ & $1.2^{\mathrm{b}}$ \\
Cholesterol removed & - & $90.0^{\mathrm{a}}$ & $90.3^{\mathrm{a}}$ \\
\hline
\end{tabular}

${ }^{\mathrm{a}, \mathrm{b}}$ Means within a row with the same letter are not different $(P<$ 0.05).

${ }^{1}$ Control $=$ butter made without treatment with crosslinked $\beta$-cyclodextrin ( $\beta$-CD) and no evening primrose oil (EPO) and phytosterols added; Trt $\mathrm{A}=$ butter made by treatment with $10 \%$ crosslinked $\beta$ $\mathrm{CD}$; Trt $\mathrm{B}=$ butter made by treatment with $10 \%$ crosslinked $\beta$-CD and with 3\% EPO and 5\% phytosterol added.

observed at $400 \times$ magnification using a photomicroscope.

\section{Statistical Analysis}

Data from determination of the optimum conditions were analyzed by one-way ANOVA (SAS Institute, 1985). The significance of the results was analyzed by the least significant differences test. A difference of $P$ $<0.05$ was considered to be significant.

\section{RESULTS AND DISCUSSION}

\section{Rate of Cholesterol Removal and Butter Composition}

The cholesterol content of the control butter was 210 $\mathrm{mg} / 100 \mathrm{~g}$, and the cholesterol reduction reached 90.0 to $90.3 \%$ with the $10 \%$ crosslinked $\beta$-CD treatment (Trt A; Table 1). This result was in accordance with our previous study using powdered $\beta$-CD, in which we reached a $92.1 \%$ cholesterol reduction rate in butter (Jung et al., 2005). In addition, the efficient removal of more than $90 \%$ cholesterol by using crosslinked $\beta$-CD has been found in other dairy products (Kim et al., 2004; Han et al., 2005; Kim et al., 2005).

A number of studies have indicated that cholesterol removal from dairy products is most effectively achieved by using powdered $\beta$-CD (Oakenfull and Sihdu, 1991; Makoto et al., 1992; Kwak et al., 2002; Shim et al., 2003; Hwang et al., 2005; Kim et al., 2005; Kwak et al., 2005; Lee et al., 2005). Although using powdered $\beta$-CD allows cholesterol removal from milk $(\sim 90 \%)$, it appears to be ineffective for separation of cholesterol or $\beta$-CD from a food system.

To overcome these problems, immobilization of $\beta$-CD on a solid support and crosslinking were attempted in our laboratory. Using immobilized $\beta-\mathrm{CD}$, the highest cholesterol removal rate was at most 40 to $50 \%$ in milk (Kwak et al., 2004), whereas with $\beta$-CD crosslinked by
Table 2. Color changes in cholesterol-reduced butter manufactured with different treatments ${ }^{1}$

\begin{tabular}{llcr}
\hline & \multicolumn{3}{c}{ Color value } \\
\cline { 2 - 4 } Treatment & $\mathrm{L}$ & $\mathrm{a}$ & $\mathrm{b}$ \\
\hline Control & $72.1^{\mathrm{b}}$ & $-3.3^{\mathrm{a}}$ & $9.0^{\mathrm{b}}$ \\
Trt A & $78.8^{\mathrm{a}}$ & $-2.9^{\mathrm{b}}$ & $9.4^{\mathrm{b}}$ \\
Trt B & $76.1^{\mathrm{a}}$ & $-2.9^{\mathrm{b}}$ & $10.2^{\mathrm{a}}$ \\
\hline
\end{tabular}

${ }^{\mathrm{a}, \mathrm{b}}$ Means within a column with the same superscript letter are not different $(P<0.05)$.

${ }^{1}$ Control $=$ butter made without treatment with crosslinked $\beta$-cyclodextrin ( $\beta$-CD) and no evening primrose oil (EPO) and phytosterols added; Trt $\mathrm{A}=$ butter made by treatment with $10 \%$ crosslinked $\beta$ CD; Trt B = butter made by treatment with $10 \%$ crosslinked $\beta$-CD and with $3 \%$ EPO and 5\% phytosterol added.

epicholorohydrin, the cholesterol removal rate was in the range of 79.4 to $83.3 \%$ and the recycling rate reached more than $90 \%$ throughout, with 7 repeated uses (Kim et al., 2004). The cholesterol removal rate increased to greater than $90 \%$ when using crosslinked $\beta$-CD made with adipic acid, with 8 reuses (Han et al., 2005).

The moisture content was the highest in Trt B (19.0\%), and the control butter showed a significantly lower moisture content compared with the others (Table 1). No differences were found in the other chemical components except protein. These results indicated that both the crosslinked $\beta$-CD treatment and the addition of phytosterols and EPO did not significantly affect the chemical composition of the butter.

\section{Color}

The color change of the experimental butter is shown in Table 2. There was a significant difference in the "L" values between the control and experimental samples, with the experimental samples being whiter than the control. The "a" value of the control was significantly different from those in the control. The control butter showed more greenness, and Trt B, which was treated with $\beta$-CD and had EPO and phytosterols added, resulted in a more yellowish color.

\section{TBA Value}

Polyunsaturated fatty acids such as EPO are known to be susceptible to oxidation, resulting in rancidity and the development of an unpleasant odor and flavor. This potential for an oxidized off-flavor and taste to develop could be the main problem that would need to be overcome in butter with added EPO. Therefore, we determined the TBA value of butter with EPO and phytosterols added, as shown in Figure 1.

The TBA value of Trt B was 3.0, which was significantly higher than those of the control and Trt A (1.2 


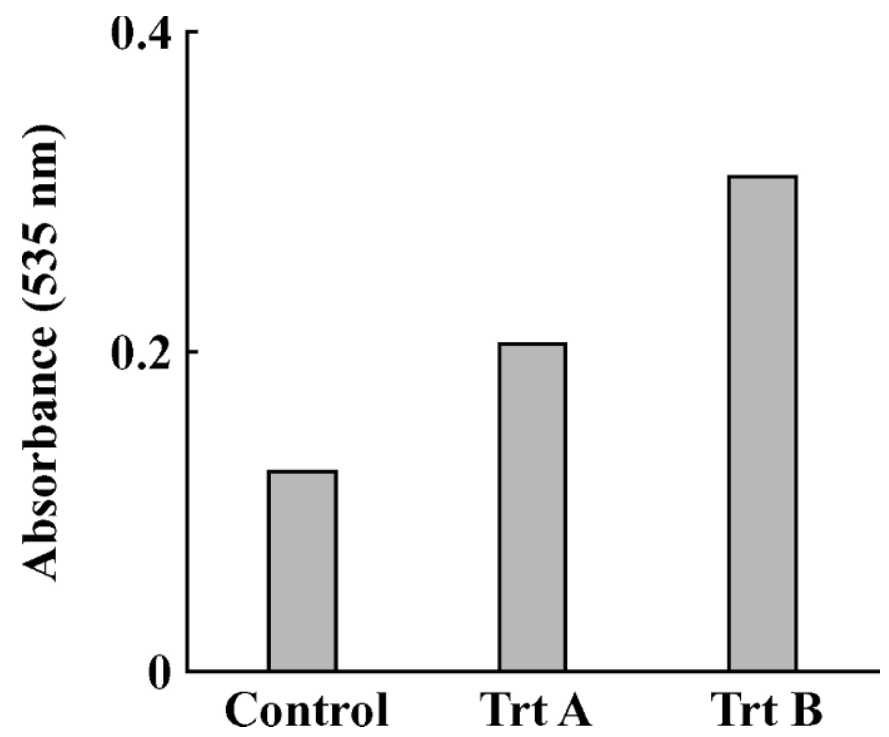

Figure 1. Changes in the thiobarbituric acid value in cholesterolreduced butter with added evening primrose oil and phytosterols. Control, not treated with crosslinked $\beta$-cyclodextrin $(\beta$-CD) and with no added evening primrose oil (EPO) and phytosterols; Trt A, treated with $10 \%$ crosslinked $\beta$-CD; Trt B, treated with $10 \%$ crosslinked $\beta$ $\mathrm{CD}$ and with $3 \% \mathrm{EPO}$ and 5\% phytosterols added.

and 2.0, respectively). Therefore, this result may indicate that lipid oxidation proceeded more rapidly in butter with added EPO and phytosterols than in the others. $\beta$-Cyclodextrin treatment of the cream also slightly increased the TBA value during butter manufacture.

These results are in accordance with other similar studies (Hwang et al., 2005; Jung et al., 2005). In their experiments, the increase in TBA absorbance was proportional to the storage period and the amount of EPO added.

\section{Rheological Characteristics}

The effects of adding EPO and phytosterols and treatment with $\beta$-CD on the rheological properties of cholesterol-reduced butter are shown in Table 3. The hardness, elasticity, and cohesiveness values were significantly higher in Trt A than in the control. When the rheological properties of the control were compared with Trt B, no difference was found in any of the properties except elasticity.

The present study showed that treatment with $\beta$-CD increased the hardness, elasticity, and cohesiveness of the butter, whereas the addition of EPO and phytosterols resulted in decreased values for the rheological properties, a result probably caused by the addition of EPO and phytosterols in liquid form.

\section{Sensory Evaluation}

The sensory attributes of butter with EPO and phytosterols added are shown in Table 4. Across all the sensory properties, no significant difference was found between the control and Trt A $(P<0.05)$. However, a significant difference was shown between the control and Trt B. This result indicated that the $\beta$-CD treatment may not have resulted in a change in sensory properties, whereas fortification with EPO and phytosterols in addition to $\beta$-CD treatment may have induced major impairments in most sensory aspects of the butter. In particular, the rancidity and overall acceptability scores changed dramatically when EPO and phytosterols were added. Apparently, these differences were attributable not to the $\beta$-CD treatment but to the addition of EPO and phytosterols. In addition, the high value for spreadability was attributable to the lower viscosity of the EPO and phytosterols at room temperature.

A similar study (Kim et al., 2006) indicated that a high amount of EPO addition (5\%) resulted in a profoundly adverse effect on the overall quality of Cheddar cheese throughout the $8 \mathrm{wk}$ of ripening. However, a small amount of EPO (1\%) did not result in any adverse effect on the sensory characteristics.

The high, significant scores for rancidity and overall acceptability in butter treated with $\beta$-CD with added EPO and phytosterols probably resulted from the EPO itself or was derived from the oxidation of fat. Interestingly, there was no difference in texture scores between the experimental butter and the control, and the color

Table 3. Textural properties of cholesterol-reduced butter manufactured with different treatments ${ }^{1}$

\begin{tabular}{llllll}
\hline Treatment & Hardness & Elasticity & Cohesiveness & Gumminess & Chewiness \\
\hline Control & $170.5^{\mathrm{b}}$ & $79.6^{\mathrm{b}}$ & $43.8^{\mathrm{b}}$ & $35.6^{\mathrm{ab}}$ & $31.6^{\mathrm{ab}}$ \\
Trt A & $253.5^{\mathrm{a}}$ & $84.2^{\mathrm{a}}$ & $55.4^{\mathrm{a}}$ & $37.8^{\mathrm{a}}$ & $33.8^{\mathrm{a}}$ \\
Trt B & $156.9^{\mathrm{b}}$ & $73.4^{\mathrm{c}}$ & $39.1^{\mathrm{b}}$ & $33.2^{\mathrm{b}}$ & $29.2^{\mathrm{b}}$ \\
\hline
\end{tabular}

\footnotetext{
${ }^{\mathrm{a}, \mathrm{b}}$ Means within column with the same letter are not significantly different $(P<0.05)$.

${ }^{1}$ Control $=$ butter made without treatment with crosslinked $\beta$-cyclodextrin $(\beta$-CD) and no evening primrose oil (EPO) and phytosterols added; Trt $\mathrm{A}=$ butter made by treatment with $10 \%$ crosslinked $\beta$-CD; Trt $\mathrm{B}=$ butter made by treatment with $10 \%$ crosslinked $\beta$-CD and with $3 \%$ EPO and $5 \%$ phytosterol added.
} 
Table 4. Sensory characteristics of cholesterol-reduced butter manufactured with different treatments ${ }^{1}$

\begin{tabular}{lllllllllll}
\hline & \multicolumn{8}{c}{ Sensory descriptions } \\
\cline { 2 - 10 } Treatment & Texture & Color & Greasiness & Off-flavor & $\begin{array}{l}\text { Butter } \\
\text { flavor }\end{array}$ & Sourness & $\begin{array}{l}\text { Butter } \\
\text { taste }\end{array}$ & Rancidity & Spreadability & $\begin{array}{l}\text { Overall } \\
\text { acceptability }\end{array}$ \\
\hline Control & $2.9^{\mathrm{a}}$ & $2.9^{\mathrm{a}}$ & $2.9^{\mathrm{b}}$ & $3.0^{\mathrm{a}}$ & $2.9^{\mathrm{b}}$ & $3.0^{\mathrm{ab}}$ & $2.9^{\mathrm{a}}$ & $3.0^{\mathrm{b}}$ & $2.9^{\mathrm{b}}$ & $3.5^{\mathrm{b}}$ \\
Trt A & $2.8^{\mathrm{a}}$ & $2.8^{\mathrm{a}}$ & $2.8^{\mathrm{b}}$ & $3.0^{\mathrm{a}}$ & $3.0^{\mathrm{b}}$ & $2.9^{\mathrm{b}}$ & $2.9^{\mathrm{a}}$ & $3.0^{\mathrm{b}}$ & $2.9^{\mathrm{b}}$ & $3.4^{\mathrm{b}}$ \\
Trt B & $2.9^{\mathrm{a}}$ & $2.9^{\mathrm{a}}$ & $3.1^{\mathrm{a}}$ & $3.1^{\mathrm{a}}$ & $3.1^{\mathrm{a}}$ & $3.1^{\mathrm{a}}$ & $2.8^{\mathrm{a}}$ & $3.8^{\mathrm{a}}$ & $3.1^{\mathrm{a}}$ & $2.8^{\mathrm{a}}$ \\
\hline
\end{tabular}

a,b Means within the column with the same letter are not different $(P<0.05)$.

${ }^{1}$ Control $=$ butter made without treatment with crosslinked $\beta$-cyclodextrin $(\beta$-CD) and no evening primrose oil (EPO) and phytosterols added; Trt $\mathrm{A}=$ butter made by treatment with $10 \%$ crosslinked $\beta$-CD; Trt $\mathrm{B}=$ butter made by treatment with $10 \%$ crosslinked $\beta$-CD and with $3 \%$ EPO and 5\% phytosterol added.

was even more yellowish in the EPO-added group, which may be more preferred by consumers.

In another study examining the effect of EPO addition on the sensory properties of yogurt (Lee et al., 2005 ), the properties most affected were rancidity and off-taste, in accordance with the present study. With the addition of EPO, the most profound change was found in the sensory properties, especially with higher amounts of EPO ( 3 and $5 \%$ ). Most of the sensory properties were highly impaired with a higher amount of EPO, and the difference was significant in every ripening period $(P<0.05)$. This may have been due mainly to the EPO itself or to the susceptibility of EPO to lipid oxidation in milk fat. Even though the addition of EPO showed a profoundly adverse effect, a low amount of EPO, for example, a $1 \%$ addition, did not result in significant differences in most sensory characteristics. Therefore, the present study showed the possibility of adding EPO to butter.

With the addition of phytosterol esters, the most profound change was found in the rancidity score. The rancidity and off-flavor scores increased dramatically with the addition of phytosterol esters, and the difference was significant $(P<0.05)$. This may have been due mainly to the phytosterol esters being susceptible to lipid oxidation. Even though the addition of phytosterol esters had a profoundly adverse effect on rancidity and off-flavor, a low amount of phytosterol esters, for example, a $4 \%$ addition, did not result in significant differences in most of the sensory characteristics, even in rancidity and off-flavor. Therefore, this study showed the possibility of adding phytosterol esters to cholesterol-reduced butter.

\section{Microscopic Observation}

The microstructure of the 3 samples was observed using photomicroscopy (Figure 2). No distinguishable differences were found among the 3 different butters. In all samples, a smooth texture and fine, uniform crystalline structure were observed. In the Trt B butter, large clumps of crystals characterizing EPO or phytosterols were observed. Birefringence, which is indicative of the presence of crystalline fat, was seen in the Trt $\mathrm{B}$ butter and was practically nonexistent in the control butter.

The control butter seemed to have less crystalline fat, as indicated by its smoother surface, which was due to the absence of EPO and phytosterols. In the Trt B butter, some irregularly sized crystals were likely because of packing of the EPO and phytosterol molecules in the crystal lattice, which was influenced by the variety of molecular sizes present in the fat source.

Butter is a water-in-oil type emulsion containing about $80 \%$ milk fat, $16 \%$ emulsified water, $2 \%$ salt, and $2 \%$ protein. The fat phase in butter comprises various triglycerides with melting points ranging from -40 to $+40^{\circ} \mathrm{C}$. In this temperature range, fat exists partly in a crystalline state. The degree of crystallinity depends on the concentrations of different triglycerides present. Interactions among fat crystals lead to the formation of a 3-dimensional network structure and provide consistency to the product. Thus, the microstructure of butter is dependent on its chemical composition, and the nature of the microstructure in turn affects its rheological properties such as spreadability, hardness, mouthfeel, and emulsion stability (Shukla et al., 1994).

To control and manipulate the textural characteristics of butter and fat spreads, the study of a product's microstructure and the relationship of the microstructure to its chemical composition and rheological properties are of vital importance. Understanding such relationships can provide useful insights into developing fat spreads with desirable functional attributes. Although the chemical composition, microstructure, and rheological properties of butter have been extensively studied in the past (Shukla et al., 1994), these studies have been limited to only one of these properties.

\section{CONCLUSIONS}

The present study designed to develop a cholesterolreduced butter with EPO and phytosterols added, and 

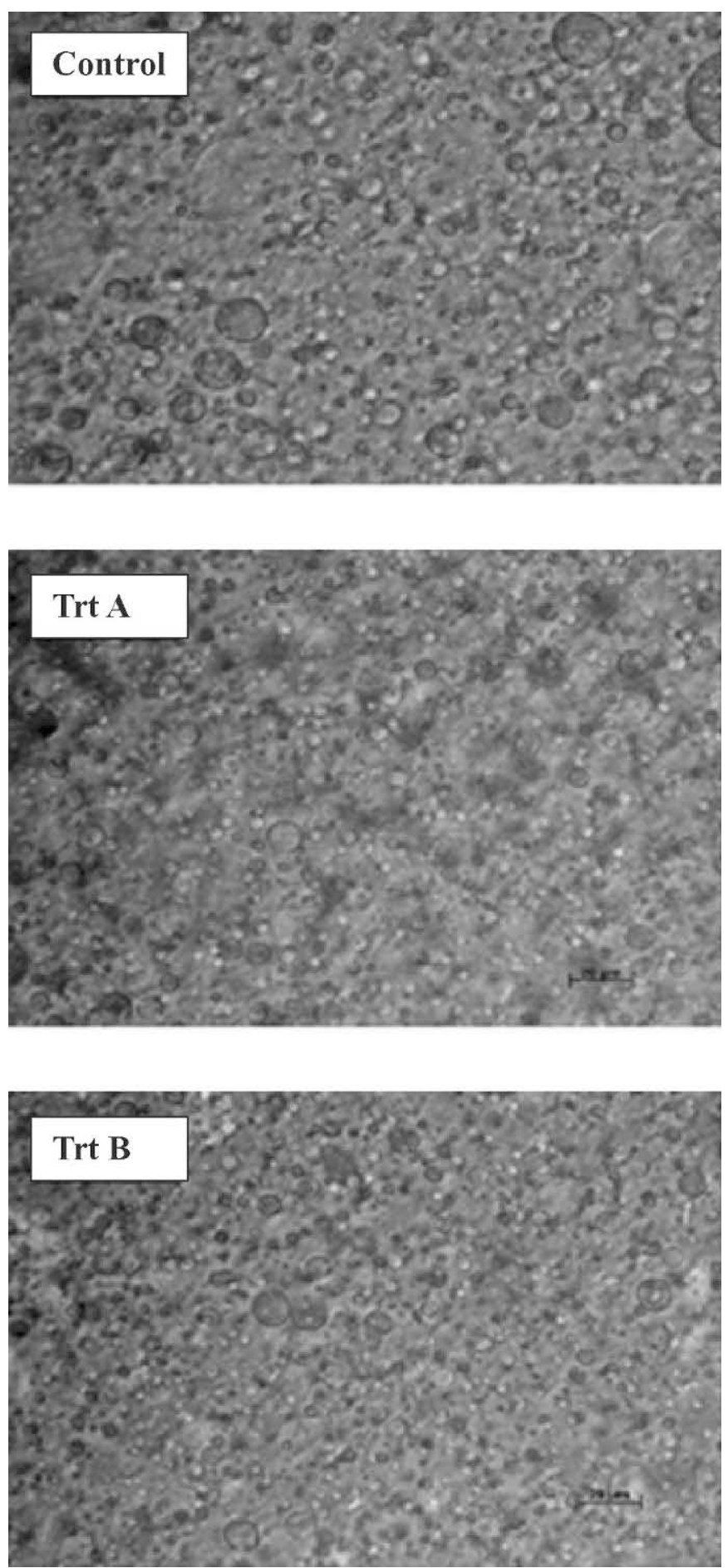

Figure 2. Comparison of the microstructure of the control butter (top), butter treated with crosslinked $\beta$-CD (Trt A, middle), and butter treated with crosslinked $\beta$-CD and with EPO and phytosterols added (Trt B, bottom) as observed by photomicroscopy.

to examine the effect of treatment with crosslinked $\beta$ $\mathrm{CD}$ and addition of EPO and phytosterols on the chemical, textural, and sensory aspects of the product. As expected, the TBA value of the cholesterol-reduced butter increased with the addition of EPO and phytosterols. Among the sensory properties, greasiness, butter taste, spreadability, rancidity, and overall acceptability were mostly influenced in Trt B compared with the control and Trt A products. These results may be attributed to lipid oxidation of the EPO and phytosterols added. However, treatment with crosslinked $\beta$-CD did not have a significantly adverse effect on the chemical, rheological, or sensory aspects of the butter in the present study. Therefore, this study indicates that using crosslinked $\beta$-CD could be an effective way to remove cholesterol from butter. The addition of EPO and phytosterols could be applied to butter manufacture; however, more research is needed to reduce lipid oxidation and to mask rancidity during processing.

\section{ACKNOWLEDGMENTS}

This study was supported by the Brain Korea 21 Project, Seoul, Korea.

\section{REFERENCES}

Adams, M. L., D. M. Sullivan, R. L. Smith, and E. F. Richer. 1986. Evaluation of direct saponification method in determination of cholesterol in meats. J. Assoc. Anal. Chem. 69:844-846.

AOAC. 1990. Official Methods of Analysis, Vol. 1. 15th ed. AOAC International, Arlington, VA.

Arthur, C. 1990. The cholesterol market. Am. Demographics 12:10-12.

Best, D. 1989. Diet and health bring vitality to a maturing market. Prepared Foods 158:111-114.

Cochran, W. G., and G. M. Cox. 1957. Experimental Designs. John Wiley \& Sons, New York, NY.

Expert Panel on Detection. 2001. Executive summary of the third report of the National Cholesterol Education Program (NCEP) expert panel on detection, evaluation, and treatment of high blood cholesterol in adults (adult treatment panel III). JAMA 285:2486-2497.

Grundy, S. M., D. Brheimer, H. Blackburn, W. V. Brown, P. O. Kwiterovich, F. Mattson, G. Schonfeld, and W. H. Weidman. 1982. Rational of the diet-heart statement of the American Heart Association Report of the Nutrition Committee. Circulation 65:839A-854A.

Hamerstrand, G. E., B. T. Hofreiter, and C. L. Mehltretter. 1959. Determination of the extent of reaction between epichlorohydrin and starch. Cereal Chem. 37:519-524.

Han, E. M., S. H. Kim, J. Ahn, and H. S. Kwak. 2005. Cholesterol removal from homogenized milk with crosslinked $\beta$-cyclodexterin by adipic acid. Asian-Austral. J. Anim. Sci. 18:1794-1799.

Hegenauer, J., P. Saltman, D. Ludwig, L. Ripley, and P. Bajo. 1979. Effects of supplemental iron and copper on lipid oxidation in milk. 1. Comparison of metal complexes in emulsified and homogenized milk. J. Agric. Food Chem. 27:860-867.

Hepburn, P. A., S. A. Horner, and M. Smith. 1999. Safety evaluation of phytosterol esters. Part 2. Subchronic 90-day oral toxicity study on phytosterol esters-A novel functional food. Food Chem. Toxicol. 37:521-532.

Horrobin, D. F., and M. S. Manku. 1983. How do polyunsaturated fatty acids lower plasma cholesterol levels? Lipids 18:558-562.

Hudson, B. J. F. 1984. Evening primrose (Oenothera spp.) oil and seed. J. Am. Oil Chem. Soc. 61:540-543.

Hwang, J. H., S. J. Lee, and H. S. Kwak. 2005. Properties and cholesterol lowering effect of cholesterol-reduced milk supplemented 
with evening primrose oil. Asian-Austral. J. Anim. Sci. 18:1041-1047.

Ihara-Watanabe, M., H. Umekawa, T. Takahashi, and Y. Furuichi. 1999. Effects of dietary $\alpha$ - or $\gamma$-linolenic acid on levels and fatty acid compositions of serum and hepatic lipids, and activity and mRNA abundance of 3-hydroxy-3-methylglutaryl CoA reductase in rats. Comp. Biochem. Physiol. A 122:213-220.

International Dairy Statistics. 2003. Page 98 in World per capita consumption of butter. Dairy Australia, Victoria, South Bank, Australia.

Jung, T. H., J. J. Kim, S. H. Yu, J. Ahn, and H. S. Kwak. 2005. Properties of cholesterol-reduced butter and effect of $\gamma$-linolenic acid added butter on blood cholesterol. Asian-Austral. J. Anim. Sci. 18:1646-1654.

Kim, S. H., J. Ahn, and H. S. Kwak. 2004. Crosslinking of $\beta$-cyclodextrin on cholesterol removal from milk. Arch. Pharm. Res. 27:1183-1187.

Kim, S. H., E. M. Han, J. Ahn, and H. S. Kwak. 2005. Effect of crosslinked $\beta$-cyclodextrin on quality of cholesterol-reduced cream cheese. Asian-Austral. J. Anim. Sci. 18:584-589.

Kim, J. J., S. H. Yu, W. M. Jeon, and H. S. Kwak. 2006. The effect of evening primrose oil on chemical and blood cholesterol lowering in properties of Cheddar cheese. Asian-Austral. J. Anim. Sci. 19:450-458.

Kwak, H. S., H. J. Ahn, and J. Ahn. 2005. Development of phytosterol ester-added Cheddar cheese for lowering blood cholesterol. AsianAustral. J. Anim. Sci. 18:267-276.

Kwak, H. S., C. S. Jung, S. Y. Shim, and J. Ahn. 2002. Removal of cholesterol from Cheddar cheese by $\beta$-cyclodextrin. J. Agric. Food Chem. 50:7293-7298.

Kwak, H. S., S. H. Kim, J. H. Kim, H. J. Choi, and J. M. Kang. 2004. Simple immobilization of $\beta$-cyclodextrin to remove cholesterol in milk and recycling. Arch. Pharm. Res. 27:873-877.
Lee, S. J., J. S. Hwang, S. Lee, J. Ahn, and H. S. Kwak. 2006. Property changes and cholesterol lowering effect in evening primrose oiladded and cholesterol-reduced yogurt. Int. J. Dairy Technol. (accepted)

Leeson, P., and E. Flöter. 2002. Solidification behaviour of binary sitosteryl esters mixtures. Food Res. Int. 35:983-991.

Ling, W. H., and P. J. H. Jones. 1995. Dietary phytosterols: Review of metabolism, benefits and side-effects. Life Sci. 57:196-206.

Makoto, K., O. Akio, and Reijiro, S. 1992. Cholesterol removal from animal with cyclodextrin by inclusion. Honnen LTD., assignee. Japanese Pat. No. 4,168,198.

Morton, G. M., S. M. Leem, D. H. Buss, and P. Lawrence. 1995. Intakes and major dietary sources of cholesterol and phytosterols in the British diet. J. Hum. Nutr. Diet. 8:429-440.

Nagamoto, S. 1985. Cyclodextrin-expanding the development of their functions and applications. Chem. Econ. Eng. Rev. 17:28-34.

Oakenfull, D. G., and G. S. Sidhu. 1991. Cholesterol reduction. Commonwealth scientific and industrial research organization, assignee. Int. Pat. No. 91/11114.

SAS Institute. 1985. Users Guide: Statistics, Version 5 ed. SAS Inst., Inc., Cary, NC.

Shim, S. Y., J. Ahn, and H. S. Kwak. 2003. Functional properties of cholesterol-removed whipping cream treated by $\beta$-cyclodextrin. J. Dairy Sci. 86:2767-2772.

Shukla, A., A. R. Bhaskar, S. S. H. Rizvi, and S. J. Mulvaney. 1994. Physicochemical and rheological properties of butter made from supercritically fractionated milk fat. J. Dairy Sci. 77:45-54.

Sugano, M., T. Ide, T. Ishida, and K. Yoshida. 1986. Hypocholesterolemic effect of $\gamma$-linolenic acid as evening primrose oil in rats. Ann. Nutr. Metab. 30:289-299.

Weststrate, J. A., and G. W. Meijer. 1998. Plant sterol-enriched margarines and reduction of plasma total- and LDL-cholesterol concentrations in normocholesterolemic and mildly hypercholesterolemic subjects. Eur. J. Clin. Nutr. 52:334-343.

Wilson, B. 1990. Race for cholesterol-free butter. Dairy Ind. Int. 55:7. 